\title{
Heat Capacity, Heats of Fusion and Vaporization, and Vapor Pressure of Tetrafluoroethylene
}

\author{
George T. Furukawa, Robert E. McCoskey, and Martin L. Reilly
}

\begin{abstract}
The heat capacity of tetrafluoroethylene of $99.99_{0}$-mole-percent purity was measured in an adiabatic calorimeter from $16^{\circ}$ to $210^{\circ} \mathrm{K}$. A smoothed table of heat capacity at 5-degree intervals from $0^{\circ}$ to $210^{\circ} \mathrm{K}$ was constructed from the data. The average heat of fusion of three experiments gave $7,714.5 \pm 7$ abs $\mathrm{j}_{\text {mole }}^{-1}$ at the triple-point temperature of $142.00 \pm 0.01^{\circ} \mathrm{K}$. The three heats of vaporization measurements at the normal boiling temperature of $197.53 \pm 0.01^{\circ} \mathrm{K}$ gave an average value of $16,821 \pm 10 \mathrm{abs} \mathrm{j} \mathrm{mole}^{-1}$. The results of the vapor-pressure measurements from $142^{\circ}$ to $208^{\circ} \mathrm{K}$ can be represented by the equation

$$
\log _{10} p_{\mathrm{mmHg}}=4.71241-\frac{972.9810}{T}+4.816562 \times 10^{-2} T-2.427347 \times 10^{-4} T^{2}+3.958793 \times 10^{-7} T^{3} .
$$

The entropy of the ideal gas tetrafluoroethylene at $197.53^{\circ} \mathrm{K}$ and 1 atm was computed from the calorimetric data to be $270.06 \pm 0.37$ abs j $\mathrm{deg}^{-1} \mathrm{~mole}^{-1}$ or $64.55 \pm 0.09 \mathrm{cal} \mathrm{deg}^{-1}$ mole $^{-1}(1 \mathrm{cal}=4.1840$ abs $\mathrm{j})$. The entropy was computed from molecular and spectroscopic

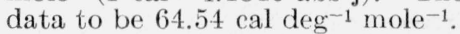

\section{Introduction}

In continuation of the program for the thermodynamic investigation of high temperature resistant polymers and their respective monomers or prototype molecules, heat-capacity, heats of fusion and vaporization, and vapor-pressure measurements were conducted with tetrafluoroethylene $\left(\mathrm{C}_{2} \mathrm{~F}_{4}\right)$. This substance has recently become important as the monomer in the production of polytetrafluoroethylene (Teflon) plastic, which has exceedingly high chemical and thermal stability. Heat-capacity studies with this polymer have recently been reported from the National Bureau of Standards. ${ }^{2}$

\section{Apparatus and Method}

The heat-capacity and heat-of-fusion measurements with tetrafluoroethylene were made in an adiabatic calorimeter which has been previously described. ${ }^{3}$ The heat of vaporization was determined in another adiabatic calorimeter constructed by R. B. Scott of the Bureau. This calorimeter was similar in design to those described by Osborne and Ginnings ${ }^{4}$ and by Aston, et al, ${ }^{5}$ in which a throttle valve was contained within the space enclosed by the adiabatic shield. Briefly, during the vaporization experiments a known electric power was supplied continuously, and the vapor was removed isothermally from the calorimeter by controlling the throttle valve. The material removed from the calorimeter in a measured time interval, was collected by condensation in a small high-pressure cylinder $(150 \mathrm{ml})$ and weighed.

1 This paper is based on the work sponsored by the Ordnance Corps, U. S. Department of the Army.

${ }_{2}$ G. T. Furukawa, R. E. McCoskey, and G. J. King, J. Research NBS 49, 273 (1952) R P2364.

${ }^{3}$ R. B. Scott, C. H. Mejers, R. D. Rands, Jr., F. G. Brickwedde, and N. Bekkedah!, J. Research NBS 35, 39 (1945) RP1661.

4 N. S. Osborne and D. C. Ginnings, J. Research NBS 39, 453 (1947) R P1841. s J. G. Aston, H. L. Fink, G. J. Janz, and K. E. Russell, J. Am. Chem. Soc. 73, 1939 (1951).
In the vapor-pressure measurements the same calorimeter used for the vaporization measurements served as a thermostated container. No provision was made to stir the sample. The pressures were read by means of a mercury manometer and a mirrorbacked glass scale. The readings were converted to standard $\mathrm{mm} \mathrm{Hg}\left(\mathrm{g}=980.665 \mathrm{~cm} / \mathrm{sec}^{2}\right.$, temperature $=$ $0^{\circ} \mathrm{C}$ ) on the basis that the local gravity is 980.076 $\mathrm{cm} / \mathrm{sec}^{2}$.

The International Temperature Scale ${ }^{6}$ was used, and below $90^{\circ} \mathrm{K}$, a provisional scale ${ }^{7}$ was used based on a set of platinum resistance thermometers calibrated against a helium-gas thermometer.

\section{Material}

The sample was originally received in a high-pressure cylinder (300 g. to $1.5 \mathrm{ft}^{3}$ ) and inhibited against polymerization and other reactions. To remove the inhibitor, the material was passed through a train of gas-washing bottles containing concentrated sulfuric acid, and to remove traces of permanent gases, it was later frozen and pumped three times. About $155 \mathrm{~g}$ of the purified material was collected. As this substance is considered to be hazardous, particularly in the uninhibited state, it was kept at temperatures below that of dry-ice at all times, except when being weighed.

The purity of the material was determined in the calorimeter before the thermal measurements from the equilibrium melting temperatures ${ }^{8}$ on the bases that no solid solution was formed and that the liquid solution followed Raoult's law. The equilibrium temperatures and the corresponding reciprocal of the fraction melted, $F$, are given in table 1.

\footnotetext{
${ }^{8}$ H. F. Stimson, J. Research NBS 42, 209 (1949) RP1962

${ }^{7}$ H. J. Hoge and F. G. Brickwedde, J. Research NBS 22, 351 (1939) RP1188.

8 G. T. Furukawa, D. C. Ginnings, R. E. MeCoskey, and R. A. Nelson, J. Research NBS 46, 195 (1951) RP2191.
} 
TABLE 1. Equilibrium melting temperatures of tetrafluoroethylene

\begin{tabular}{l} 
Mole fraction impurity $=0.0460 \Delta T,{ }^{\circ} \mathrm{K}=273.1$ \\
$\qquad$\begin{tabular}{c|c}
\hline $\begin{array}{c}\text { Reciprocal of } \\
\text { fraction melted, } \\
1 / F\end{array}$ & $T$ \\
\hline & \\
9.59 & ${ }^{\circ} \mathrm{K}$ \\
4.73 & 141.9762 \\
3.67 & 141.9936 \\
1.93 & 142.0959 \\
1.46 & 142.0012 \\
1.21 & 142.0016 \\
0.00 & $\mathrm{~s} 142.0048$ \\
\hline Triple-point temperature, \\
$142.00 \pm 0.01^{\circ} \mathrm{K}$. \\
\hline
\end{tabular} \\
\hline
\end{tabular}

a Extrapolated.

The data were plotted and the purity was computed from the slope of the curve to be $99.99_{0}$ mole percent. The intercept or the triple-point temperature of pure tetrafluoroethylene was found to be $142.00 \pm 0.01^{\circ} \mathrm{K}$. The results of the premelting heat-capacity measurements made during the course of this study indicated that the purity remained essentially the same. (The temperature in degrees Kelvin was obtained from the relation: ${ }^{\circ} \mathrm{K}=273.16^{\circ}$ $+{ }^{\circ} \mathrm{C}$. Whenever the temperatures are expressed in the paper to the fourth decimal place, the last two figures are significant only in the measurement of small temperature differences.)

\section{Heat Capacity}

The heat-capacity measurements were made from $16^{\circ}$ to $210^{\circ} \mathrm{K}$. In the computation to obtain the net heat capacities, the observed gross-heat capacities were first smoothed, then the smoothed tare heat capacities were subtracted at the corresponding equally spaced integral temperatures. Curvature corrections (see footnote 8) were applied to the gross and tare heat capacities wherever significant. The vapor-pressure data obtained in this work and the liquid densities reported by Ruff and Bretschneider ${ }^{9}$ were used to make vapor saturation corrections. ${ }^{10}$

The results of the heat-capacity measurements gave a precision of \pm 0.02 percent in the liquid and from \pm 0.02 to \pm 0.05 percent in the solid range, except for the lowest temperatures. There is, however, a fairly large uncertainty in the vapor-saturation correction to the heat capacity at the higher temperatures because the amount of material in the filling tube is not accurately determinable. Considering these factors, particularly the latter, and other possible sources of error, the uncertainty in the final heat-capacity values given in table 2 is believed to be \pm 0.2 percent. In table 2 the values below $15^{\circ} \mathrm{K}$ were obtained by the extrapolation (see footnote 8) of a Debye function fitted to experimental values between $16^{\circ}$ and $30^{\circ} \mathrm{K}$.

\footnotetext{
O O. Ruff and O. Bretschneider, Z. anorg. allgem. Chem, 210, 173 (1933).
}

10 H. J. Hoge, J. Research NBS 36, 111 (1946) RP1693.
TABLE 2. Molal heat capacity of tetrafuoroethylene at integral temperatures

Molecular weight $=100.02,{ }^{\circ} \mathrm{K}=273.16^{\circ}+{ }^{\circ} \mathrm{C}$.

\begin{tabular}{|c|c|c|c|}
\hline$T$ & $C_{\text {Batd. }}{ }^{\mathrm{a}}$ & $T$ & $C_{\text {satd. }}$ \\
\hline \multicolumn{2}{|c|}{ Solid } & ${ }^{\circ} \mathrm{K}$ & \multirow{6}{*}{$\begin{array}{c}\text { abs j deg }{ }^{-1} \text { mole } e^{-1} \\
73.20 \\
75.95 \\
78.90 \\
82.07 \\
85.46 \\
\text { b } 86.85\end{array}$} \\
\hline \multirow{7}{*}{$\begin{array}{r}{ }^{\circ} \boldsymbol{K} \\
0 \\
5 \\
10 \\
15 \\
20 \\
25\end{array}$} & $a b s j \mathrm{deg}^{-1}$ mole $e^{-1}$ & $\begin{array}{l}125 \\
130\end{array}$ & \\
\hline & 0.0 & 135 & \\
\hline & .33 & 140 & \\
\hline & 2. 64 & 142.00 & \\
\hline & 7. 94 & & \\
\hline & 14. 79 & \multirow{3}{*}{\multicolumn{2}{|c|}{ Liquid }} \\
\hline & 21. 29 & & \\
\hline 30 & 26.91 & & \\
\hline $\begin{array}{l}35 \\
40\end{array}$ & $\begin{array}{l}31.65 \\
35.60\end{array}$ & 142,00 & b 103 . 02 \\
\hline $\begin{array}{l}40 \\
45\end{array}$ & $\begin{array}{l}35.60 \\
38.94\end{array}$ & $\begin{array}{l}142.00 \\
145\end{array}$ & $\begin{array}{l}105.02 \\
106.11\end{array}$ \\
\hline 50 & 41.92 & 150 & 106.36 \\
\hline 55 & 44. 62 & 155 & 106.72 \\
\hline 60 & 47.11 & 160 & 107.15 \\
\hline 65 & 49.44 & 165 & 107.65 \\
\hline 70 & 51.55 & 170 & 108. 20 \\
\hline 75 & -53.61 & 175 & 108.82 \\
\hline 80 & 55. 74 & 180 & 109.49 \\
\hline 85 & 57.86 & 185 & 110.22 \\
\hline 90 & 59.92 & 190 & 111.01 \\
\hline 95 & 61.82 & 195 & 111.85 \\
\hline 100 & 63.88 & 197.53 & 112.31 \\
\hline 105 & 66.02 & & 112.77 \\
\hline 110 & 68. 26 & 205 & 113.75 \\
\hline 115 & 70.65 & 210 & 114.79 \\
\hline
\end{tabular}

a $C_{\text {satd. }}$ is the heat capacity of the condensed phase under its vapor pressure. b Extrapolated

\section{Heat of Fusion}

The determination of the heat of fusion involved continuous introduction of electrical energy from a temperature just below the triple point to just above it and the correction for the heat capacity of the sample and container. Also, a small premelting correction was applied. The results of the measurements are given in table 3 . The values given in the fifth column are the total heats required to melt the $156.2694 \mathrm{~g}$ in the claorimeter. Taking into account the precision obtained, and other possible sources of error, the uncertainty in the heat of fusion is considered to be \pm 7 abs $\mathrm{j} \mathrm{mole}^{-1}$.

TABLE 3. Molal heat of fusion of tetrafluoroethylene Molecular weight $=100.02$, mass of sample $=156.2694 \mathrm{~g}$, triple-point temperature $=142.00^{\circ} \mathrm{K},{ }^{\circ} \mathrm{K}=273.16^{\circ}+{ }^{\circ} \mathrm{C}$

\begin{tabular}{|c|c|r|r|r|r|}
\hline $\begin{array}{c}\text { Temperature } \\
\text { interval }\end{array}$ & $\begin{array}{c}\text { Heat in- } \\
\text { put }\end{array}$ & $\begin{array}{c}\text { Heat ca- } \\
\text { pacity }\end{array}$ & $\begin{array}{c}\text { Pre- } \\
\text { melt- } \\
\text { ing }\end{array}$ & $\Delta H$ & $\Delta H$ \\
\hline${ }^{\circ} K$ & $a b s j$ & $a b s j$ & $a b s j$ & $a b s j$ & $a b s j$ mole ${ }^{-1}$ \\
137.7930 to 143.7828 & $13,374.1$ & $1,326.9$ & 6.5 & $12,053.7$ & $7,715.0$ \\
136.3972 to 144.1500 & $13,755.1$ & $1,707.4$ & 4.9 & $12,052.6$ & $7,714.2$ \\
137.4175 to 143.9957 & $13,504.5$ & $1,457.7$ & 5.9 & $12,052.7$ & $7,714.3$ \\
\hline
\end{tabular}

\section{Heat of Vaporization}

The heat-of-vaporization experiments were made at the normal boiling point $\left(197.53^{\circ} \mathrm{K}\right)$ as determined by the vapor-pressure measurements. The experimentally observed quantity $\gamma$, the energy input per mole of sample collected, ${ }^{11}$ is related to the

11 N. S. Osborne, BSJ. Research 4, 609 (1930) RP168. 
molal heat of vaporization, $L$, by the expression

$$
L=\gamma-T V \frac{d p}{d T}
$$

where $V$ is the molal volume of the liquid, $T$, the absolute temperature, and $p$, the vapor pressure. The experimentally observed quantities, the value of the conversion term (second term to the right of the equality sign), and the heat of vaporization are given in table 4 . The molal volume for the conversion term was obtained from the densities of tetrafluoroethylene reported by Ruff and Bretschneider (see footnote 9). Considering the precision and other sources of error, the uncertainty in the heat of vaporization is believed to be \pm 10 abs $\mathrm{j}$ mole ${ }^{-1}$. The heat of vaporization, computed from the Clapeyron equation by using the vaporpressure equation obtained in this work, the liquid densities reported by Ruff and Bretschneider (see

TABLE 4. Molal heat of vaporization of tetrafluoroethylene at $197.53^{\circ} \mathrm{K}$ (1-atm pressure)

Molecular weight $=100.02,{ }^{\circ} \mathrm{K}=273.16^{\circ}+{ }^{\circ} \mathrm{C}$

\begin{tabular}{|c|c|c|}
\hline$\gamma$ & $T V \frac{d p}{d T}$ & $L$ \\
\hline abs j mole $e^{-1}$ & $a b s j$ mole & $a b s j$ mole $e^{-1}$ \\
16,884 & 71 & 16,813 \\
16,901 & 71 & 16,830 \\
16,890 & 71 & 16,819 \\
\hline Mean .......... & 16,821 \\
Standard deviation..... & \pm 4 \\
\hline
\end{tabular}

footnote 9), and the Berthelot equation of state, amounted to 16,850 abs $\mathrm{j}$ mole $^{-1}$. This is in fair agreement with the observed value. The constants for the Berthelot equation were reported by Renfrew and Lewis. ${ }^{12}$

\section{Vapor Pressure}

As there was no provision to stir the sample in the calorimeter, several series of vapor-pressure measurements were made from $142^{\circ}$ to $208^{\circ} \mathrm{K}$ going down the temperature scale as well as up to check the temperature equilibrium. The agreement in the results of the measurements, as shown in table 5, indicates that equilibrium conditions existed. The vapor-pressure equation fitted to the experimental values is given by

$$
\begin{aligned}
& \log _{10} p_{\mathrm{mmHg}}=4.71241-\frac{972.9810}{T}+4.816562 \\
& \times 10^{-2} T-2.427347 \times 10^{-4} T^{2}+3.958793 \times 10^{-7} T^{3}
\end{aligned}
$$

In table 5 are given the deviations of the calculated values, based on this equation, from the observed values. Although the deviations from the equation vary somewhat systematically, no attempt was made to obtain a closer-fitting equation.

The normal boiling point was taken to be 197.53 $\pm 0.01^{\circ} \mathrm{K}$, although the equation gives $197.525^{\circ} \mathrm{K}$ and the difference in the rounding can be measured by the thermometer and by the manometer. The $d p / d T$ at the normal boiling point is about $41 \mathrm{~mm}$ $\mathrm{Hg}$ per degree.

12 M. M. Renfrew and E. E. Lewis, Ind. Eng. Chem. 38, 870 (1946).

\begin{tabular}{|c|c|c|c|c|c|c|c|}
\hline$T_{\mathrm{obs}}$ & $p_{\text {obs }}$ & $p_{\text {eale }}$ & $p_{\text {obs }}-p_{\text {eale }}$ & $T_{\text {obs }}$ & $p_{\text {obs }}$ & $p_{\text {eale }}$ & $p_{\text {obs }}-p_{\text {ealc }}$ \\
\hline \multicolumn{4}{|c|}{ Series I } & \multicolumn{4}{|c|}{ Series IV } \\
\hline $\begin{array}{c}{ }^{\circ} K \\
206.66 \\
207.50 \\
208.41\end{array}$ & $\begin{array}{l}m m \mathrm{Hg} \\
1,217.8 \\
1,268.6 \\
1,325.1\end{array}$ & $\begin{array}{c}m m \mathrm{Hg} \\
1,217.5 \\
1,268.6 \\
1,325.8\end{array}$ & $\begin{array}{c}m m \mathrm{Hg} \\
0.3 \\
.0 \\
-.7\end{array}$ & \multirow{3}{*}{$\begin{array}{c}{ }^{\circ} K \\
147.70 \\
152.92 \\
155.77 \\
158.89 \\
164.15 \\
169.69 \\
175.35 \\
178.27 \\
180.96\end{array}$} & \multirow{3}{*}{$\begin{array}{l}m m \mathrm{Hg} \\
16.7 \\
28.6 \\
37.8 \\
50.5 \\
79.7 \\
124.7 \\
190.5 \\
233.9 \\
280.7\end{array}$} & \multirow{3}{*}{$\begin{array}{l}m m \mathrm{Hg} \\
16.6 \\
28.5 \\
37.6 \\
50.3 \\
79.8 \\
124.9 \\
190.7 \\
234.2 \\
281.1\end{array}$} & \multirow{3}{*}{$\begin{array}{c}m m \mathrm{Hg} \\
0.1 \\
.1 \\
.2 \\
.2 \\
-.1 \\
-.2 \\
-.2 \\
-.3 \\
-.4\end{array}$} \\
\hline \multicolumn{4}{|c|}{ Series II } & & & & \\
\hline $\begin{array}{l}175.82 \\
179.23\end{array}$ & $\begin{array}{l}197.1 \\
249.9\end{array}$ & $\begin{array}{l}197.2 \\
250.2\end{array}$ & $\begin{array}{r}-0.1 \\
-.3\end{array}$ & & & & \\
\hline $\begin{array}{l}182.01 \\
184.37 \\
186.54\end{array}$ & $\begin{array}{l}301.0 \\
350.8 \\
402.2\end{array}$ & $\begin{array}{l}301.3 \\
351.0 \\
402.2\end{array}$ & $\begin{array}{r}-.3 \\
-.2 \\
.0\end{array}$ & \multicolumn{4}{|c|}{ Series V } \\
\hline \multicolumn{4}{|c|}{ Series III } & $\begin{array}{l}142.00 \\
147.98 \\
152.3\end{array}$ & $\begin{array}{r}8.7 \\
17.1 \\
26.9\end{array}$ & $\begin{array}{r}8.7 \\
17.1\end{array}$ & $\begin{array}{r}0.0 \\
.0\end{array}$ \\
\hline 182.96 & 320.4 & 320.6 & -0.2 & $\begin{array}{l}159.34 \\
168.56\end{array}$ & $\begin{array}{r}52.5 \\
114.3\end{array}$ & $\begin{array}{r}52.4 \\
114.3\end{array}$ & .10 \\
\hline 188. 27 & 447.0 & $\begin{array}{l}447.2 \\
44.2\end{array}$ & -.2 & 172.90 & $\begin{array}{l}159.2 \\
\text { 159. }\end{array}$ & $\begin{array}{l}159.4 \\
\end{array}$ & -.0 \\
\hline 190.11 & 499.2 & 499.3 & -1 & 178. 02 & 229.8 & 230.2 & -.4 \\
\hline 193.30 & 601.0 & 600.9 & .1 & 180.23 & 267.3 & 267.7 & -.4 \\
\hline 196.06 & 701.8 & 701.5 & .3 & 191.74 & 549.1 & 549.4 & -.3 \\
\hline 196. 06 & 701.4 & 701.5 & -.1 & & & & \\
\hline 198.41 & 797. 5 & 797. 2 & .3 & & & & \\
\hline 200.61 & 895.8 & 895.8 & 0 & & & & \\
\hline 202.84 & $1,005,6$ & $1,005.4$ & .2 & & & & \\
\hline 205.44 & $1,146.1$ & $1,146.2$ & -.1 & & & & \\
\hline 206.99 & $1,236.3$ & $1,237.4$ & -1.1 & & & & \\
\hline
\end{tabular}

TABLE 5. Vapor pressure of tetrafluoroethylene

${ }^{\circ} \mathrm{K}=273.16^{\circ}+{ }^{\circ} \mathrm{C}$ 


\section{Experimental Entropy}

The experimental data were used to compute the entropy of the ideal gas tetrafluoroethylene at $197.53^{\circ} \mathrm{K}$ and $1 \mathrm{~atm}$. In table 6 are summarized the entropy computations. The Berthelot equation of state and the critical constants reported by Renfrew and Lewis (see footnote 12) were used to compute the gas imperfection. The uncertainty of $\pm 0.37 \mathrm{abs} \mathrm{j} \mathrm{deg}^{-1} \mathrm{~mole}^{-1}$ for the entropy of ideal gas $\mathrm{C}_{2} \mathrm{~F}_{4}$ at $197.53^{\circ} \mathrm{K}$ and $1 \mathrm{~atm}$ was obtained by statistically combining the uncertainty in the entropy of liquid $\mathrm{C}_{2} \mathrm{~F}_{4}$ at $197.53^{\circ} \mathrm{K}$ and in the entropy of vaporization. The uncertainty in the gas imperfection correction was considered negligible.

In terms of the thermochemical calorie $(1 \mathrm{cal}=$ $4.1840 \mathrm{abs} \mathrm{j}$ ) the calorimetric entropy of the ideal gas tetrafluoroethylene becomes $64.55 \pm 0.09$ cal $\operatorname{deg}^{-1}$ mole $^{-1}$.

TABLE 6. Summary of the Molal entropy of tetrafluoroethylene Molecular weight $=100.02,{ }^{\circ} \mathrm{K}=273.16^{\circ}+{ }^{\circ} \mathrm{C},{ }^{1} 1 \mathrm{cal}=4.1840 \mathrm{abs} \mathrm{j}$

\begin{tabular}{|l|c|}
\hline & \\
& abs $j$ deg ${ }^{-1}$ mole -1 \\
$S_{16^{\circ}}$ (Debye) & 3.42 \\
$\Delta S_{16^{\circ}}$ to $142.00^{\circ}$ Solid, numerical integration & 90.73 \\
$\Delta S_{142.00^{\circ}}$ fusion, $7714.5 / 142.00$ & 54.33 \\
$\Delta S_{142^{\circ}}$ to $197.53^{\circ}$, liquid, numerical integration & $184.23 \pm 0.37$ \\
Entropy of the liquid at $197.53^{\circ} \mathrm{K}$ & $85.16 \pm 0.05$ \\
$\Delta S_{197.53^{\circ}}$ vaporization $16821 / 197.53$ & 0.67 \\
$\Delta S_{197.53^{\circ}}$ gas imperfection & $270.06 \pm 0.37$ \\
Entropy, ideal gas at $197.53^{\circ} \mathrm{K}$ and $1 \mathrm{~atm}^{\circ}$ & \\
&
\end{tabular}

Washington, March 13, 1953.

\section{Entropy From Molecular and Spectro- scopic Data}

The entropy due to the external rotation was computed from the molecular constants taken from the electron diffraction results of Karle and Karle ${ }^{13}$ in which the $\mathrm{C}-\mathrm{F}$ and $\mathrm{C}=\mathrm{C}$ bond distances and the FCF angle were given as $1.313 \pm 0.010 \mathrm{~A}, 1.313$ $\pm 0.035 \mathrm{~A}$, and $114 \pm 2^{\circ}$, respectively. The moments of inertia calculated were $I_{x}=152.9 \times 10^{-40} \mathrm{~g}-\mathrm{cm}^{2}$, $I_{y}=254.7 \times 10^{-40} \mathrm{~g}-\mathrm{cm}^{2}$, and $I=407.6 \times 10^{-40}$ $\mathrm{g}-\mathrm{cm}^{2}$. The fundamental constants used in the computation were essentially those given in the National Bureau of Standards Circular $461 .^{14}$

The vibrational contribution to the entropy was computed from the recent frequency assignments of D. E. Mann, N. Aquista, and E. K. Plyler at the Bureau.

The entropy computed from the molecular and spectroscopic data is summarized and compared with the calorimetric entropy in table 7 . An excellent agreement is shown in the two results.

TABLE 7. Molal entropy of tetrafluoroethylene at $197.53^{\circ} \mathrm{K}$ from molecular and spectroscopic data

Molecular weight $=100.02,{ }^{\circ} \mathrm{K}=273.16^{\circ}+{ }^{\circ} \mathrm{C} ., 1 \mathrm{cal}=4.1840 \mathrm{abs}$ j.

\begin{tabular}{|l|c|}
\hline S, translation & cal deg mole $^{-1}$ \\
37.67 & 22.58 \\
S, external rotation $\ldots .29$ \\
S, vibration
\end{tabular}

13 I. L. Karle and J. Karle, J. Chem. Phys. 18, 963 (1950),

16 F. D. Rossini, K. S. Pitzer, W. J. Taylor, J. P. Ebert, J. E. Kilpatrick, C. W Beckett, M. G. Williams, and H. G. Werner, NBS Circular 461 (November 1947). 